Article

\title{
A Simple Up-Scalable Thermal Treatment Method for Synthesis of ZnO Nanoparticles
}

\author{
Phin Jit Lee ${ }^{1}$, Elias Saion ${ }^{1}$, Naif Mohammed Al-Hada ${ }^{1, *}$ and Nayereh Soltani ${ }^{2}$ \\ 1 Department of Physics, Faculty of Science, Universiti Putra Malaysia, 43400 UPM Serdang, \\ Selangor 43300, Malaysia; E-Mails: leephinjit@yahoo.com (P.J.L.); elias@ upm.edu.my (E.S.) \\ 2 Young Researchers and Elite Club, Shahr-e-Qods Branch, Islamic Azad University, \\ Tehran 37541-374, Iran; E-Mail: nayereh.soltani@gmail.com \\ * Author to whom correspondence should be addressed; E-Mail: naifalhada@upm.edu.my; \\ Tel.: +60-17233-43-27; Fax: +60-38945-44-54.
}

Academic Editors: Vineet V. Joshi and Alan Meier

Received: 9 October 2015 / Accepted: 8 December 2015 / Published: 14 December 2015

\begin{abstract}
A simple thermal treatment method, utilizing only zinc nitrate, polyvinyl pyrrolidone (PVP), and deionized water, was used to synthesize $\mathrm{ZnO}$ nanoparticles, and their characteristics were investigated by various techniques. The TGA measurement demonstrated that the bulk of the capping agent PVP can be removed at temperatures higher than $500{ }^{\circ} \mathrm{C}$ and is consistent with the absence of the majority of PVP absorption peaks in the FT-IR spectra. The formation of almost pure $\mathrm{ZnO}$ nanoparticles was established by the presence of single absorption peak in the FT-IR spectra due to being only $\mathrm{Zn}-\mathrm{O}$ bonds at calcination temperatures of $500{ }^{\circ} \mathrm{C}$ and above. The TEM images revealed that the nanoparticles have a spherical shape and the particle size increased from 60.1-83.1 nm with an increase in calcination temperatures from $500-600{ }^{\circ} \mathrm{C}$. The XRD diffraction patterns indicated that the particles are of a wurzite lattice structure. The optical properties were determined by $\mathrm{UV}-\mathrm{Vis}$ spectrophotometer, and it was found that the band gap of $\mathrm{ZnO}$ nanoparticles decreased from 3.249-3.239 $\mathrm{eV}$ with an increase in calcination temperature from $500-600{ }^{\circ} \mathrm{C}$.
\end{abstract}

Keywords: ZnO nanostructures; TGA; FTIR; XRD; TEM; UV-Vis spectrophotometer 


\section{Introduction}

$\mathrm{ZnO}$, a II-IV semiconductor which is one of the favourable candidates among metal oxides in nanoelectronic science, has a wide bandgap of $3.37 \mathrm{eV}$ at room temperature, high exciton binding energy (60 meV), and perfect stability under ambient conditions [1-3]. Due to its unique and fascinating structural, thermal, optical, electronic, and magnetic properties, different particle sizes of $\mathrm{ZnO}$ have been widely fabricated for transistors, light-emitting devices, solar cells, piezoelectric devices, photocatalysts, photovoltaic, gas sensors, and field-emission devices as well as chemical and biological sensors [4-7].

To fulfil the demand of $\mathrm{ZnO}$ in diverse technological applications, extensive investigations for finding a suitable synthesis technique have been conducted to produce $\mathrm{ZnO}$ nanoparticles of appropriate morphology and size that could be useful for all kinds of applications, and yet has potential for scaling up and large-scale production. Various methods have been used to synthesize $\mathrm{ZnO}$ nanoparticles including the sol-gel technique [8,9], thermal decomposition process [10], sonochemical method [11], and laser ablation [12]. However, these methods rely on complex handling procedures, long reaction times, and dangerous reagents and they produce toxic by-products, which make them unsuitable for large-scale production. The trend for large-scale production of nanoparticles is to use low cost precursors, simple processes, consume less energy, and minimize environmental impacts, requiring no further size selection procedures [13]. Recently, a simple and potential up-scalable thermal treatment route has been developed in our laboratory for synthesis of various nanomaterials [14-18]. The method offers advantages in its simplicity, and it is environmentally friendly as it neither uses toxic reagent nor produces toxic by-products.

In this article, we present the fabrication of pure $\mathrm{ZnO}$ nanoparticles using a thermal treatment method by dissolving metal precursor, zinc nitrate and a capping agent, polyvinyl pyrrolidone (PVP), in deionized water before drying and grinding with simultaneous sintering and calcination. The physical properties of the prepared $\mathrm{ZnO}$ nanoparticles were investigated using thermogravimetric analysis (TGA), Fourier transform infrared analysis (FT-IR), X-ray diffraction (XRD), transmission electron microscopy (TEM), and UV-Visible spectroscopy.

\section{Experimental Section}

Zinc nitrate used as metal source with a purity exceeding $99 \%$ was purchased from Acros Organics (New Jersey, NJ, US). The polyvinyl pyrrolidone (PVP, MW =10,000 g/mol) used as capping agent to reduce particle agglomeration was purchased from Sigma Aldrich (Darmstadt, Germany). All the chemicals were used without further purification. Deionized water was obtained from Di-Pack ${ }^{\circledR}$ Millipore (Waltham, MA, US) and used as solvent.

In a typical synthesis procedure, $10 \mathrm{mM}$ of $\mathrm{Zn}\left(\mathrm{NO}_{3}\right)_{2} \cdot 6 \mathrm{H}_{2} \mathrm{O}$ was introduced into $3.5 \mathrm{wt}$ \% PVP and the solution was stirred for $4 \mathrm{~h}$. The transparent pale yellow solution was dried in an oven at $80{ }^{\circ} \mathrm{C}$ for $24 \mathrm{~h}$. The dried solid cake was ground for $20 \mathrm{~min}$ in a mortar to form powder and named as-prepared sample. Some as-prepared samples were calcined at different temperatures from $450-700{ }^{\circ} \mathrm{C}$ in a furnace for $3 \mathrm{~h}$ with the objective of removing PVP and leaving behind pure $\mathrm{ZnO}$ nanoparticles.

TGA analysis was performed using Mettler Toledo TGA/SDTA 851Eand (Im Langacher Greifensee, Switzerland) ran at $10{ }^{\circ} \mathrm{C} / \mathrm{min}$ under atmospheric environment from room temperature to $700{ }^{\circ} \mathrm{C}$. The 
FT-IR was performed using Perkin Elmer Spectrum 100 (Labexchange, Swabian Burladingen, Germany) in the range of $250-4000 \mathrm{~cm}^{-1}$. The XRD measurements were accomplished by Philips PW3050/60 PAN analytical (Lelyweg1, Almelo, The Netherlands) using copper anode at $\mathrm{Cu} \mathrm{K \alpha}$ wavelength of $1.54 \AA$ for $2 \theta$ angles from $4^{\circ}-80^{\circ}$. The TEM images were evaluated by LEO $912 \mathrm{AB}$ EFTEM (Munich, German). The $\mathrm{ZnO}$ nanoparticles were dispersed in acetone (95\%) by ultrasonification and dried on copper grids for TEM measurement. The diffuse reflectance spectra were measured using a UV-vis spectrophotometer (Shimadzu model UV-3600, Kyoto, Japan) in the range of 200-800 nm at room temperature to evaluate the optical properties of $\mathrm{ZnO}$ nanoparticles.

\section{Results and Discussion}

The TGA analysis of as-prepared sample is depicted in Figure 1. The massive mass loss of almost $77 \%$ occurred from room temperature up to $500{ }^{\circ} \mathrm{C}$ due to trapped moisture below $100{ }^{\circ} \mathrm{C}$ and organic matter (PVP) below $460{ }^{\circ} \mathrm{C}$ of the sample. The TGA result was used to investigate the thermal stability of the sample during the process of heat treatment. The residue of the sample shown in the TGA spectrum is the $\mathrm{ZnO}$ nanoparticles are thermally almost stable starting at $500{ }^{\circ} \mathrm{C}$ and continuing up to the maximum temperature of $700{ }^{\circ} \mathrm{C}$.

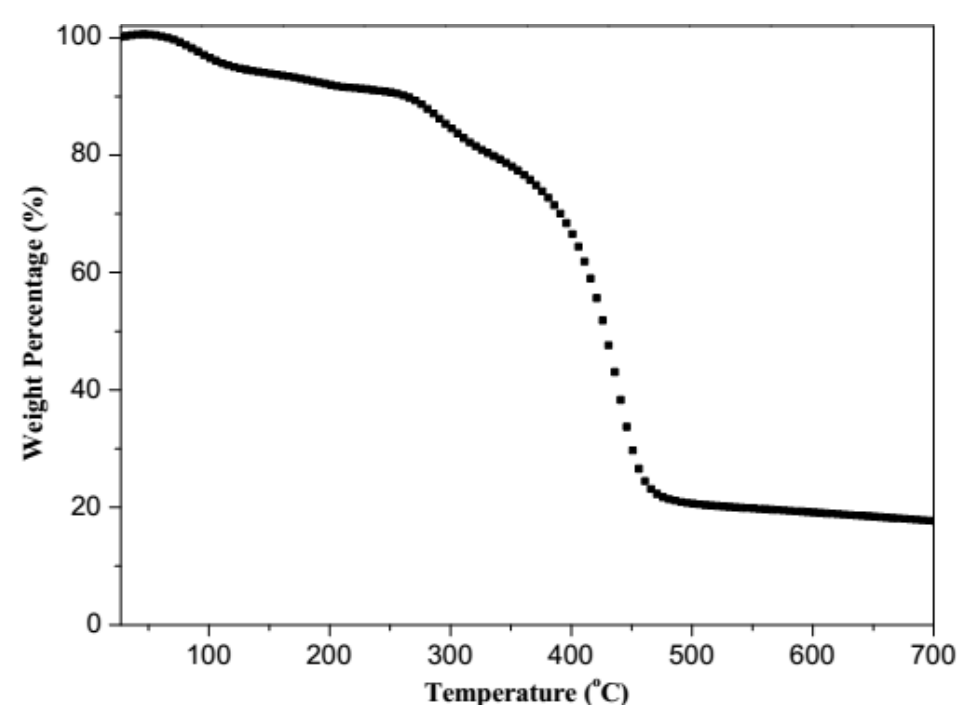

Figure 1. TGA analysis of as-prepared sample.

The FT-IR spectra of the as-prepared sample and synthesized $\mathrm{ZnO}$ nanoparticles are displayed in Figure 2. As can be seen in the figure, there are several characteristic absorption bands appearing in the range of $250-4000 \mathrm{~cm}^{-1}$ due to covalent bonds of PVP $[16,19,20]$. The peaks located at 3262 and $2948 \mathrm{~cm}^{-1}$ represent the vibration mode of $\mathrm{O}-\mathrm{H}$ group of the moisture and the stretching mode of anti-symmetry $\mathrm{CH}_{2}$, respectively. The presence of hydroxyl at peaks of 1646 and $1426 \mathrm{~cm}^{-1}$ came from surface adsorption of surrounding water and residual product. It is ascribed as the $\mathrm{O}-\mathrm{H}$ bending of water partly overlapping with stretching vibration of $\mathrm{C}=\mathrm{O}$ asymmetrical and bending $\mathrm{CH}_{2}$ in $\alpha$ position of $\mathrm{C}=\mathrm{O}$. The peak located at $1372 \mathrm{~cm}^{-1}$ is described to be the stretching vibration of nitrate $\left(\mathrm{NO}_{3}{ }^{-}\right)$band; while the spectrum peak at $1280 \mathrm{~cm}^{-1}$ is the $\mathrm{C}-\mathrm{N}$ stretching vibration band. The peaks from 1068 and $569 \mathrm{~cm}^{-1}$ are attributed as the stretching $\mathrm{C}-\mathrm{C}$ rings of "breathing" of pyrrolidone. The peak at $368 \mathrm{~cm}^{-1}$ is assigned to be the stretching of $\mathrm{Zn}-\mathrm{O}$ bond. We expect the same peaks of PVP are present below calcination 
temperatures of $400{ }^{\circ} \mathrm{C}$ because the mass loss of the sample is slightly changed as indicated by TGA curve. At calcinations temperature of $450{ }^{\circ} \mathrm{C}$, most of the appeared peaks in the as-prepared sample were removed except the peaks at $3377,1508,834$, and $389 \mathrm{~cm}^{-1}$ which are ascribed as the remaining small amount of PVP compounds, while the sharp peak at $389 \mathrm{~cm}^{-1}$ is typical of a $\mathrm{Zn}-\mathrm{O}$ bond. When the calcination temperature was increased, to $500{ }^{\circ} \mathrm{C}$, we observed unwanted trace peaks below $1000 \mathrm{~cm}^{-1}$ possibly due to metal nitride, and an intense peak of $389 \mathrm{~cm}^{-1}$ that come from the $\mathrm{Zn}-\mathrm{O}$ stretching bond of pure $\mathrm{ZnO}$ nanoparticles. As shown in Figure 2, the formation of $\mathrm{ZnO}$ nanocrystals started at $500{ }^{\circ} \mathrm{C}$ and this is consistent with TGA result where the majority of PVP compounds can be removed from the residue at temperatures of $500{ }^{\circ} \mathrm{C}$ and beyond.

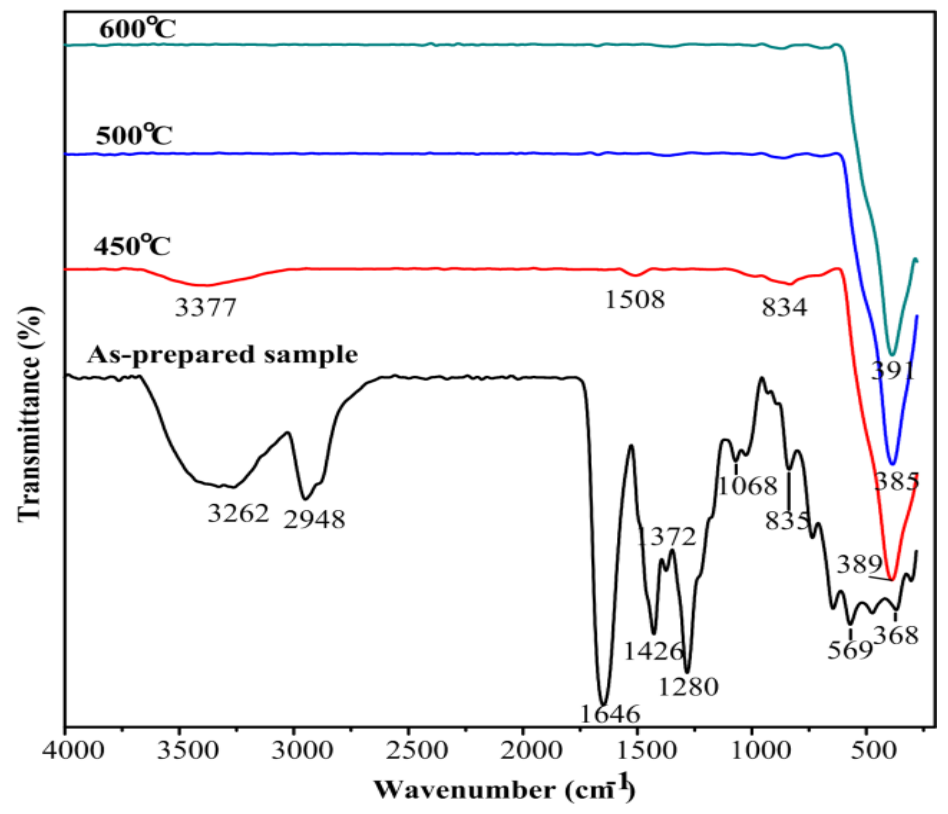

Figure 2. FT-IR spectra of as-prepared sample and $\mathrm{ZnO}$ nanoparticles at different calcination temperatures.

Figure 3 demonstrates the XRD patterns of as-prepared sample and the $\mathrm{ZnO}$ nanoparticles calcined at 450,500 , and $600^{\circ} \mathrm{C}$. The broad spectrum of as-prepared sample shows that the sample is an amorphous. On the other hand, the multiple peaks of diffraction patterns for calcined samples showed the polycrystalline property of synthesized $\mathrm{ZnO}$ nanoparticles with a wurzite structure. The diffraction peaks are coincided with the (100), (002), (101), (102), (110), (103), (200), (112), (201), (004), and (201) crystalline plans of wurzite structure of $\mathrm{ZnO}$ (ICDD 00-036-1451). At higher values of calcination temperatures, we observed an enhancement of the crystallinity of the $\mathrm{ZnO}$ nanoparticles as shown by increasing the intensity of the peaks. This crystallinity enhancement with increasing calcination temperatures is stemmed from the increment of the crystalline volume to surface ratio, as evidenced by TEM images, which occurred due to particle size enlargement [21]. The crystalline size $(D)$ of $\mathrm{ZnO}$ nanocrystals can be determined using Debye-Scherrer formula [22]:

$$
D=\frac{0.9 \lambda}{\beta \cos \theta}
$$


where $\lambda$ is the $X$-ray wavelength, $\theta$ is the Bragg's angle, and $\beta$ is the full width of the diffraction line at half maximum intensity measured in radian. The crystallite sizes of $\mathrm{ZnO}$ nanocrystals thermal treated at different temperatures were obtained from preferred plane of (101) and are listed in Table 1. The average crystalline size increases with increases of calcination temperature. The $d$-spacing of lattice planes $\left(d_{h k l}\right)$ can be determined based on Bragg's formula [23]:

$$
d_{h k l}=\frac{n \lambda}{2 \sin \theta}
$$

and the lattice parameters in hexagonal (wurzite) structure can be calculated by the following formula [23]:

$$
\frac{1}{d_{h k l}^{2}}=\frac{4}{3}\left(\frac{h^{2}+h k+k^{2}}{a^{2}}\right)+\frac{l^{2}}{c^{2}}
$$

The mean values of $a$ and $c$ as well as the $c / a$ ratio are very close with the standard value $(a=3.250 \AA$ and $c=5.207 \AA ; c / a=1.6021)$. In Table 1 , the crystal was contaminated with a trace of PVP at $450{ }^{\circ} \mathrm{C}$ as shown in the FTIR spectra, Figure 2. However, the crystallinity was not well established at this temperature and it could not be used to justify the crystalline structure at the calcination temperature. Therefore, at calcination temperatures of 500 and $600{ }^{\circ} \mathrm{C}$ in Table 1, the crystallinity of the particles were well developed and the lattice parameters are shown to be temperature dependent as the particle size increased with the calcination temperature.

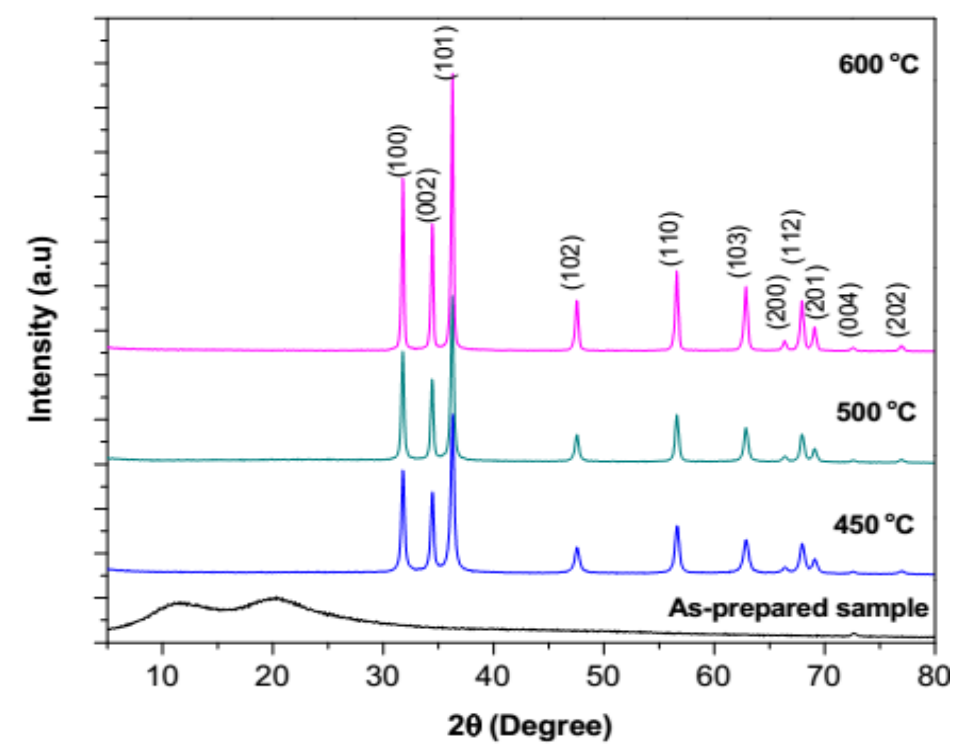

Figure 3. X-ray diffraction spectra of as-prepared sample and $\mathrm{ZnO}$ nanoparticles at different calcination temperatures.

\begin{tabular}{|c|c|c|c|c|c|}
\hline \multirow{2}{*}{$\begin{array}{c}\text { Calcination } \\
\text { Temperature }\left({ }^{\circ} \mathrm{C}\right)\end{array}$} & \multirow{2}{*}{$d$-Spacing $(\AA)$} & \multirow{2}{*}{ Crystalline Size (nm) } & \multicolumn{2}{|c|}{ Lattice Parameter $(\AA)$} & \multirow{2}{*}{$c / a$ Ratio } \\
\hline & & & $a$ & $c$ & \\
\hline 450 & 2.4769 & 30.1 & 3.2506 & 5.2090 & 1.6023 \\
\hline 500 & 2.4781 & 37.6 & 3.2499 & 5.2065 & 1.6022 \\
\hline 600 & 2.4774 & 50.7 & 3.2516 & 5.2088 & 1.6019 \\
\hline
\end{tabular}

Table 1. Structural parameters of $\mathrm{ZnO}$ nanocrystals from XRD pattern for (101) plane. 
Figure 4 illustrates the TEM micrographs of $\mathrm{ZnO}$ nanoparticles calcined at different temperatures. It is obvious that the prepared $\mathrm{ZnO}$ nanoparticles are almost a spherical shape. The average size of the synthesized $\mathrm{ZnO}$ nanoparticles are $34.14,60.17$, and $83.15 \mathrm{~nm}$ at 450,500 , and $600{ }^{\circ} \mathrm{C}$ respectively, which shows that the average particle size increased with increasing calcination temperature. These results indicate that the attained particle size increased with increasing calcination temperature due to the fact that as the temperature rises, many neighbouring particles were prone to fuse together to form larger particles as their surfaces melted [24-26]. At higher calcination temperatures above $600{ }^{\circ} \mathrm{C}$, the average particle size increased to greater than $100 \mathrm{~nm}$ and they became microstructures. It is apparent that each particle of $\mathrm{ZnO}$ nanoparticles was composed of a number of nanocrystallites; thus, the size of particles actually is much larger than that of crystalline.
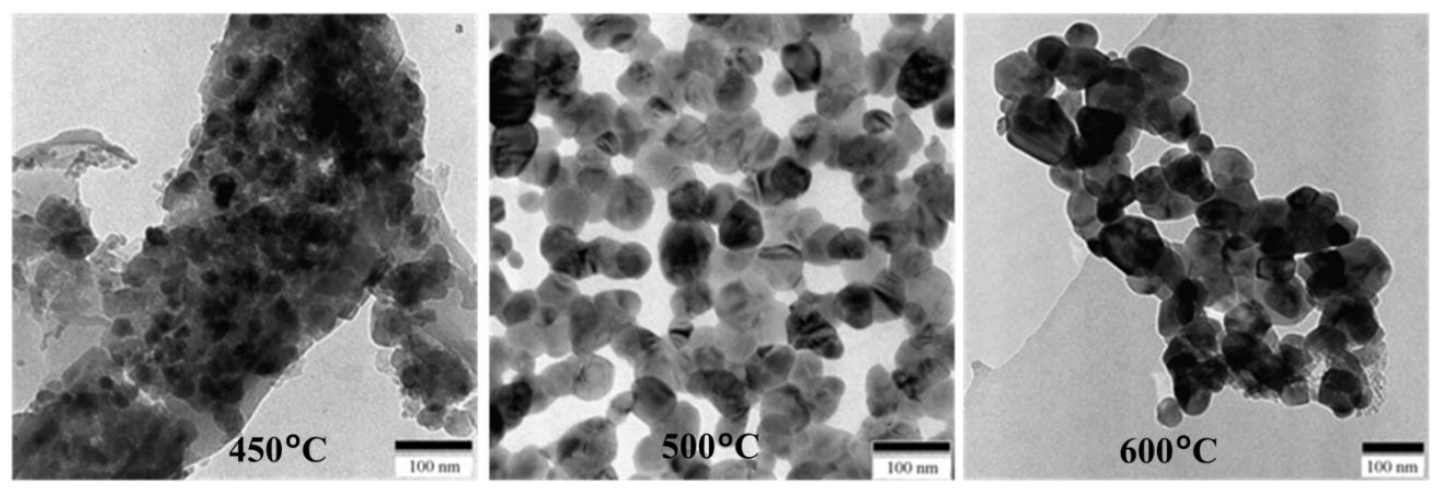

Figure 4. TEM micrographs of $\mathrm{ZnO}$ nanoparticles at different calcination temperatures.

Diffuse reflectance spectra were determined using a UV-Visible spectrophotometer. This diffuse reflectance technique is capable of collecting the reflected flux of light after interacting with the $\mathrm{ZnO}$ samples. The technique compared the reflected light fluxes coming from the surfaces of $\mathrm{ZnO}$ nanoparticles and the standard reference sample. The diffuse reflectance spectra were measured in the range of 200-800 $\mathrm{nm}$ at room temperature and are shown in Figure 5.

The optical band gap values for all samples calcined at different temperatures were determined from reflectance spectra using the Kubelka-Munk equation [23]:

$$
(\mathrm{F}(R \infty) \cdot h v)^{2}=A\left(h v-E_{\mathrm{g}}\right)
$$

where $\mathrm{F}(R \infty)$ is the so-called remission parameter or Kubelka-Munk function, $(h v)$ is the incident photon energy, $A$ is a constant depending on the transition probability and the diffuse reflectance $(R \infty),(R \infty)$ is the diffuse reflectance that is obtained from $R \infty=R_{\text {sample }} / R_{\text {standard. }}$ The values of $(\mathrm{F}(R \infty) \cdot h v)^{2} v s$. $(h v)$ were plotted as illustrated in Figure 6. The straight line ranges of the plot were extended to the $(h v)$ axis in order to determine the optical band gap values of the $\mathrm{ZnO}$ nanoparticles at different calcination temperatures. It was found that the optical band gap decreased with increasing calcination temperature from $3.249 \mathrm{eV}$ at $450{ }^{\circ} \mathrm{C}$ to $3.239 \mathrm{eV}$ at $600{ }^{\circ} \mathrm{C}$ as shown in Table 2. A decrease in the band gap with increasing calcination temperature is attributed to the increase in the particle size due to fusion of surface atoms which improved the metal crystallinity, as was evidenced by XRD analysis. It is believed that as the particle size increased, the number of atoms that form a particle also increases, which consequently renders the valence and conduction electrons more attractive to the ion core of the particles, and hence decreasing the band gap of the particles. 


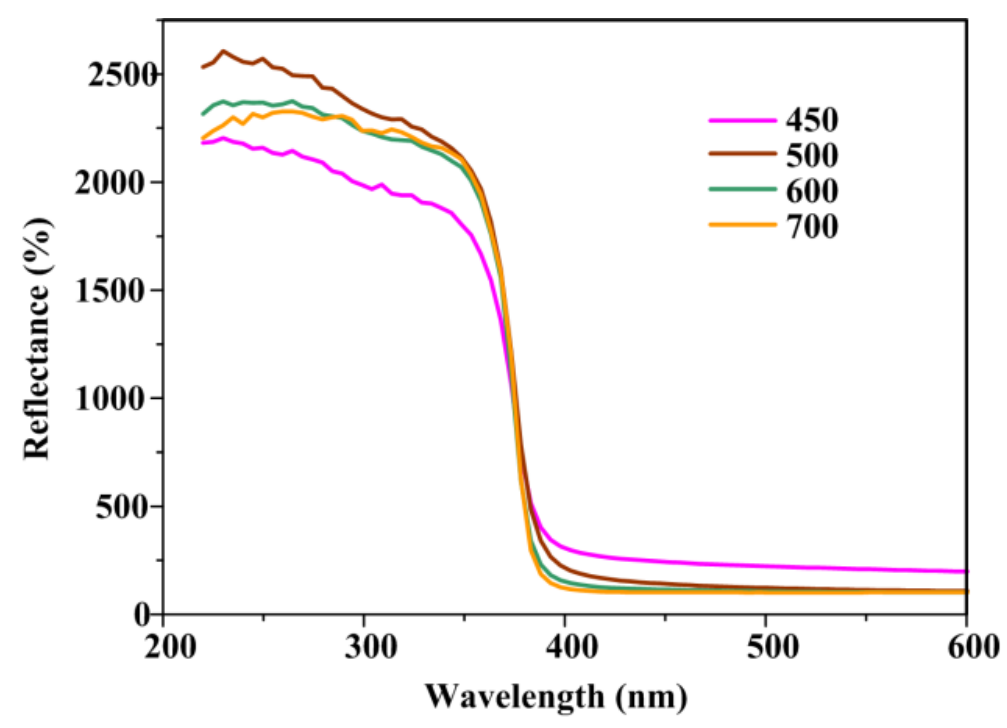

Figure 5. UV-visible diffuse reflectance spectra of $\mathrm{ZnO}$ nanoparticles at different calcination temperatures.

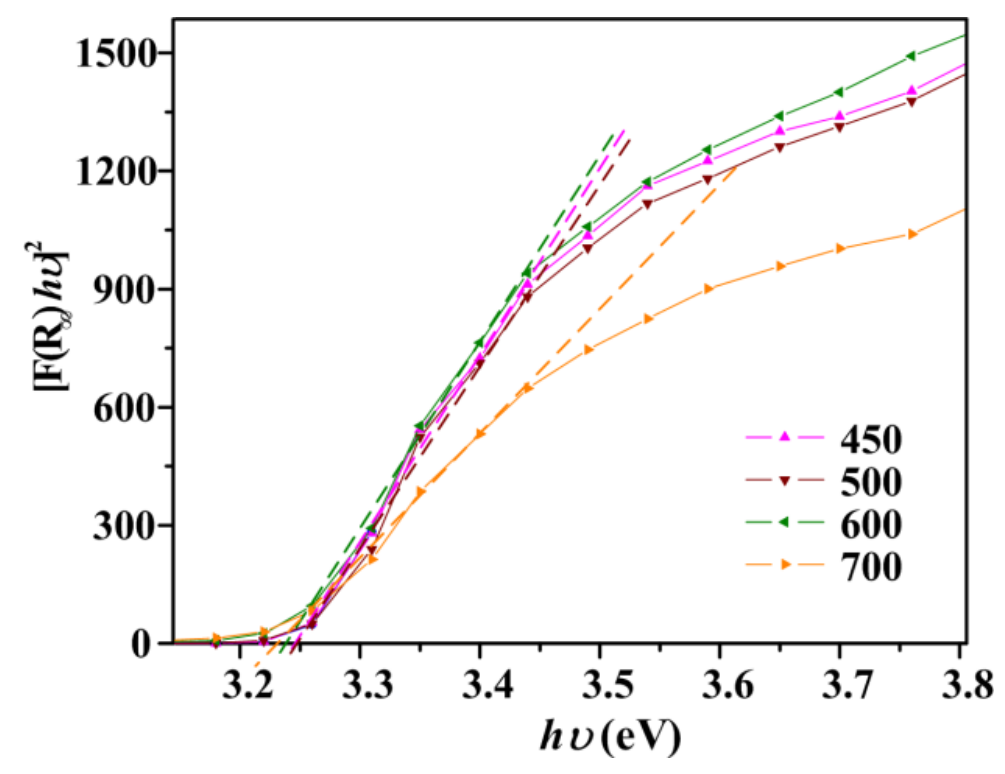

Figure 6. $(\mathrm{F}(R \infty) \cdot h v)^{2} v s$. $(h v)$ plots of of $\mathrm{ZnO}$ nanoparticles at different calcination temperatures.

Table 2. Average particle size and band gap energy of $\mathrm{ZnO}$ nanoparticles at different calcination temperatures.

\begin{tabular}{ccc}
\hline Calcination Temperature $\left({ }^{\circ} \mathbf{C}\right)$ & Average Particle Size $(\mathbf{n m})$ & Band Gap $\boldsymbol{E}_{\mathbf{g}}(\mathbf{e V})$ \\
\hline 450 & 34.14 & 3.249 \\
500 & 60.17 & 3.246 \\
600 & 83.15 & 3.239 \\
\hline
\end{tabular}

\section{Conclusions}

$\mathrm{ZnO}$ nanoparticles have been prepared by a simple and potentially up-scalable thermal treatment method which is easy to perform at low cost, and is an environmentally friendly procedure. The removal of PVP from the as-prepared sample to create pure $\mathrm{ZnO}$ nanoparticles was achieved by polymer 
calcinations and material annealing at $500{ }^{\circ} \mathrm{C}$ and above. The particle size increased with increases in calcination temperature due to the fusion of surface atoms at higher temperatures which improved the metal crystallinity. The band gap decreased with increasing calcination temperature, which was attributed to the increase in particle size. This is as a result of stronger Coulomb forces acting on the valence and conduction electrons increasing the number of core ions of the particles.

\section{Acknowledgments}

The authors would like to thank staff of Universiti Putra Malaysia for the assistance received in completion of this work. Lee would like to thank the Malaysian Government for a scholarship she received during her study.

\section{Author Contributions}

P.J.L., E.S. and N.M.A. conceived and designed the experiments; P.J.L. performed the experiments; P.J.L., E.S., N.M.A. and N.S., analyzed the data; P.J.L., E.S., N.M.A. and N.S. contributed reagents/materials/analysis tools; P.J.L., E.S., N.M.A. and N.S., wrote the paper.

\section{Conflicts of Interest}

The authors declare no conflict of interest.

\section{References}

1. Zhang, L.; Shi, J.J. Phonon states of polar mixing optical modes in wurtzite ZnO-based coupling quantum dots. Solid State Commun. 2014, 177, 68-73.

2. Huang, C.Y.; Yang, Y.J.; Chen, J.Y.; Wang, C.H.; Chen, Y.F.; Hong, L.S.; Liu, C.S.; Wu, C.Y. P-Si nanowires/SiO $/ n-Z n O$ heterojunction photodiodes. Appl. Phys. Lett. 2010, doi:10.1063/1.3462319.

3. Shevchenko, E.V.; Talapin, D.V.; Schnablegger, H.; Kornowski, A.; Festin, Ö.; Svedlindh, P.; Haase, M.; Weller, H. Study of nucleation and growth in the organometallic synthesis of magnetic alloy nanocrystals: The role of nucleation rate in size control of CoPt3 nanocrystals. J. Am. Chem. Soc. 2003, 125, 9090-9101.

4. Akgul, G.; Akgul, F.A.; Attenkofer, K.; Winterer, M. Structural properties of zinc oxide and titanium dioxide nanoparticles prepared by chemical vapor synthesis. J. Alloy. Compd. 2013, 554, 177-181.

5. Wahab, H.; Salama, A.; El-Saeid, A.; Nur, O.; Willander, M.; Battisha, I. Optical, structural and morphological studies of $(\mathrm{ZnO})$ nano-rod thin films for biosensor applications using sol gel technique. Res. Phys. 2013, 3, 46-51.

6. Goldberger, J.; Sirbuly, D.J.; Law, M.; Yang, P. ZnO nanowire transistors. J. Phys. Chem. B 2005, 109, 9-14.

7. Hsueh, T.J.; Chang, S.J.; Hsu, C.L.; Lin, Y.R.; Chen, I. Highly sensitive ZnO nanowire ethanol sensor with Pd adsorption. Appl. Phys. Lett. 2007, doi:10.1063/1.2757605.

8. Zhao, X.; Chen, Z.; Luo, Y.; Wang, L. Giant enhanced infrared and orange emissions of ZnO nanoparticles induced by rich oxygen atmosphere. Solid State Commun. 2008, 147, 447-451. 
9. Escudero, R.; Escamilla, R. Ferromagnetic behavior of high-purity $\mathrm{ZnO}$ nanoparticles. Solid State Commun. 2011, 151, 97-101.

10. Shamsipur, M.; Pourmortazavi, S.M.; Hajimirsadeghi, S.S.; Zahedi, M.M.; Rahimi-Nasrabadi, M. Facile synthesis of zinc carbonate and zinc oxide nanoparticles via direct carbonation and thermal decomposition. Ceram. Int. 2013, 39, 819-827.

11. Banerjee, P.; Chakrabarti, S.; Maitra, S.; Dutta, B.K. Zinc oxide nano-particles-Sonochemical synthesis, characterization and application for photo-remediation of heavy metal. Ultrason. Sonochem. 2012, 19, 85-93.

12. Zamiri, R.; Zakaria, A.; Ahangar, H.A.; Darroudi, M.; Zak, A.K.; Drummen, G.P. Aqueous starch as a stabilizer in zinc oxide nanoparticle synthesis via laser ablation. J. Alloy. Compd. 2012, 516, 41-48.

13. Cui, H.; Feng, Y.; Ren, W.; Zeng, T.; Lv, H.; Pan, Y. Strategies of large scale synthesis of monodisperse nanoparticles. Recent Pat. Nanotechnol. 2009, 3, 32-41.

14. Naseri, M.G.; Saion, E.B.; Ahangar, H.A.; Hashim, M.; Shaari, A.H. Simple preparation and characterization of nickel ferrite nanocrystals by a thermal treatment method. Powder Technol. 2011, 212, 80-88.

15. Naseri, M.G.; Saion, E.B.; Ahangar, H.A.; Hashim, M.; Shaari, A.H. Synthesis and characterization of manganese ferrite nanoparticles by thermal treatment method. J. Magn. Magn. Mater. 2011, 323, 1745-1749.

16. Naseri, M.G.; Saion, E.B.; Hashim, M.; Shaari, A.H.; Ahangar, H.A. Synthesis and characterization of zinc ferrite nanoparticles by a thermal treatment method. Solid State Commun. 2011, 151, 1031-1035.

17. Al-Hada, N.M.; Saion, E.B.; Shaari, A.H.; Kamarudin, M.A.; Flaifel, M.H.; Ahmad, S.H.; Gene, A. A facile thermal-treatment route to synthesize the semiconductor $\mathrm{CdO}$ nanoparticles and effect of calcination. Mater. Sci. Semicond. Process. 2014, 26, 460-466.

18. Kamari, H.M.; Naseri, M.G.; Saion, E.B. A novel research on behavior of zinc ferrite nanoparticles in different concentration of poly(vinyl pyrrolidone)(PVP). Metals 2014, 4, 118-129.

19. Sui, X.; Liu, Y.; Shao, C.; Liu, Y.; Xu, C. Structural and photoluminescent properties of ZnO hexagonal nanoprisms synthesized by microemulsion with polyvinyl pyrrolidone served as surfactant and passivant. Chem. Phys. Lett. 2006, 424, 340-344.

20. Al-Hada, N.M.; Saion, E.B.; Shaari, A.H.; Kamarudin, M.A.; Flaifel, M.H.; Ahmad, S.H.; Gene, S.A. A facile thermal-treatment route to synthesize $\mathrm{ZnO}$ nanosheets and effect of calcination temperature. PLoS ONE 2014, doi:10.1371/journal.pone.0103134.

21. Tian, Z.R.; Voigt, J.A.; Liu, J.; Mckenzie, B.; Mcdermott, M.J.; Rodriguez, M.A.; Konishi, H.; $\mathrm{Xu}, \mathrm{H}$. Complex and oriented $\mathrm{ZnO}$ nanostructures. Nat. Mater. 2003, 2, 821-826.

22. Soltani, N.; Saion, E.; Hussein, M.Z.; Bahrami, A.; Naghavi, K.; Yunus, R.B. Microwave irradiation effects on hydrothermal and polyol synthesis of $\mathrm{ZnS}$ nanoparticles. Chalcogenide Lett. 2012, 9 , 265-274.

23. De Graef, M.; McHenry, M.E. Structure of Materials: An Introduction to Crystallography, Diffraction and Symmetry; Cambridge University Press: New York, NY, USA, 2007.

24. Al-Hada, N.M.; Saion, E.; Shaari, A.; Kamarudin, M.; Gene, S.A. The influence of calcination temperature on the formation of zinc oxide nanoparticles by thermal-treatment. Appl. Mech. Mater. 2014, 446, 181-184. 
25. Al-Hada, N.M.; Saion, E.B.; Shaari, A.H.; Kamarudeen, M.A.; Flaifel, M.H.; Gene, S.A. Synthesis, Structural and Morphological Properties of Cadmium Oxide Nanoparticles Prepared by Thermal Treatment Method; Adv. Mater. Res. 2015, 1107, 291-294.

26. Zakiyah, L.B.; Saion, E.; Al-Hada, N.M.; Gharibshahi, E.; Salem, A.; Soltani, N.; Gene, S. Up-scalable synthesis of size-controlled copper ferrite nanocrystals by thermal treatment method. Mater. Sci. Semicond. Process. 2015, 40, 564-569.

(C) 2015 by the authors; licensee MDPI, Basel, Switzerland. This article is an open access article distributed under the terms and conditions of the Creative Commons Attribution license (http://creativecommons.org/licenses/by/4.0/). 